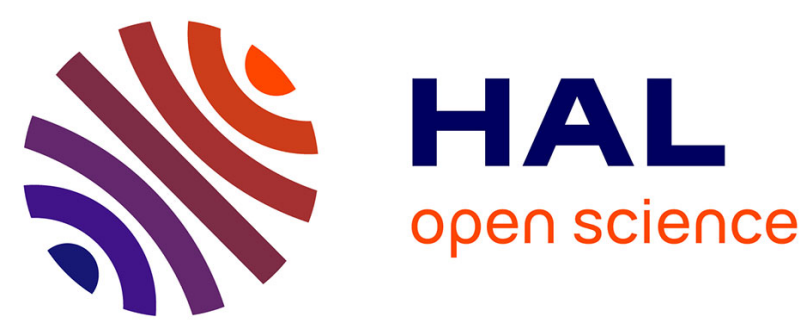

\title{
Receptance of railway tracks at low frequency: Numerical and experimental approaches
}

Elodie Arlaud, Sofia Costa d'Aguiar, Etienne Balmes

\section{To cite this version:}

Elodie Arlaud, Sofia Costa d'Aguiar, Etienne Balmes. Receptance of railway tracks at low frequency: Numerical and experimental approaches. Transportation Geotechnics, 2016, 9, pp.1-16. 10.1016/j.trgeo.2016.06.003 . hal-02569120

\section{HAL Id: hal-02569120 \\ https://hal.science/hal-02569120}

Submitted on 11 May 2020

HAL is a multi-disciplinary open access archive for the deposit and dissemination of scientific research documents, whether they are published or not. The documents may come from teaching and research institutions in France or abroad, or from public or private research centers.
L'archive ouverte pluridisciplinaire HAL, est destinée au dépôt et à la diffusion de documents scientifiques de niveau recherche, publiés ou non, émanant des établissements d'enseignement et de recherche français ou étrangers, des laboratoires publics ou privés. 


\title{
Receptance of railway tracks at low frequency: Numerical and experimental approaches
}

\author{
E. Arlaud ${ }^{\mathrm{a}, \mathrm{c}, *}$, S. Costa D'Aguiar ${ }^{\mathrm{b}}$, E. Balmes ${ }^{\mathrm{c}, \mathrm{d}}$ \\ a SNCF Reseau, Ingénierie E' Projets, 6 Avenue François Mitterrand, 93574 La Plaine Saint Denis Cedex, France \\ ${ }^{\mathrm{b}}$ SNCF, Innovation \& Research, 40 avenue des Terroirs de France, 75611 Paris Cedex 12, France \\ ${ }^{\mathrm{c}}$ Arts et Métiers ParisTech, PIMM, CNRS UMR 8006, boulevard de l'hôpital, 75013 Paris, France \\ ${ }^{\mathrm{d}}$ SDTools, 44 Rue Vergniaud, 75013 Paris, France
}

Keywords:

Railway track

Dynamic

Modeling

Receptance

\begin{abstract}
A B S T R A C T
This paper presents numerical simulations and experimental studies on the frequency domain behavior of railway track below $100 \mathrm{~Hz}$, focusing on the link between the substructure properties of the track and its global dynamic response. A numerical method in the frequency domain is first proposed and used to understand the frequency response of a railway track with a French High Speed Line (HSL) design. Then, low-frequency receptance measurements, performed in a specific HSL test site with different designs, are presented. These experimental results are used to characterize a change in the track substructure. Further analysis of the full track responses associated with peaks visible in the receptance test is conducted using numerical simulations. In the considered test case, these simulations demonstrate the existence of the superstructure and ballast resonance on relatively soft mats.
\end{abstract}

\section{Introduction}

The structure of railway tracks has changed little over years, and the few evolutions have been justified mainly on empirical bases. For instance, an experimental area of railway track over bituminous layer has been first built in the East European High Speed Line (HSL) in 2007 on $2 \mathrm{~km}$, and the favorable feedback pushed for generalization of bituminous layers in new French HSL currently under construction. However, railway tracks are costly to construct (according to Campos and deRus (2009), the average cost for high speed line construction is $17.5 \mathrm{k} € / \mathrm{m}$ of track and $19 € / \mathrm{m}$ for annual maintenance). This motivates studies on new designs reducing the need for maintenance. In

\footnotetext{
* Corresponding author at: SNCF Reseau, Ingénierie \& Projets, 6 Avenue François Mitterrand, 93574 La Plaine Saint Denis Cedex, France.

E-mail addresses: elodie.arlaud@sncf.fr (E. Arlaud), sofia.costadaguiar@sncf.fr (S. Costa D’Aguiar), balmes@sdtools.com (E. Balmes).
}

order to face this challenge, railway infrastructure managers are willing to revise specifications related to track design in order to increase the life span of their infrastructures. Introduction of under sleeper pads, of ballast mats, or improvement of bearing soil capabilities are possible solutions to do so (Esveld, 1997). Assessing the mechanical performance of these new designs from the dynamic point of view is then required.

Experimentally, a widespread practical approach to get dynamic information on the global track behavior is to perform a receptance test. That is to measure the transfer from force on rail to the associated displacement, usually through a hammer test. This test characterizes the global behavior of track for a range of frequencies and allows the identification of the main resonances of the structure: it characterizes the structure sensitivity to vibrations (Man, 2002) and the dynamic flexibility of the track (Knothe and Wu, 1998). This test is not sufficient to give full information on track dynamic behavior under passing 
trains. To do so, the knowledge of the vehicle/track interaction and of the force acting on the track is also of valuable importance (Kouroussis et al., 2014), but receptance is a first quite easy experiment to get insight on track behavior. Although the results presented in this work will focus on the track substructure, it can be noted that receptance content can also be analyzed at higher frequencies, notably to adjust numerical model properties, as pad stiffness or spring characteristics for spring-dampers models of track (Kaewunruen and Remennikov, 2007; Ribeiro, 2012; Alves Costa et al., 2012; Verbraken et al., 2013) or to detect defects on rail (Oregui et al., 2015).

Coupled with the numerical model, receptance gives insights on the wave propagation in the substructure layers, as used by Berggren et al. (2010) to assess soft soil influence. The final objective of this work is to assess the track and platform dynamic behavior under passing trains. In that case, the characteristic lengths of the system generate excitations at frequencies that depend on train speed. These excitations are mainly below $100 \mathrm{~Hz}$ (not accounting for small rail defects and irregularities). This is the cutting frequency used to study receptance curve in this work.

Several numerical models have been proposed in the literature to represent track behavior. As Finite Element Models (FEM) are widely used for engineering purposes, various authors (Hall, 2003; Araújo, 2010; Kouroussis et al., 2011; Ju and Li, 2011; Banimahd and Woodward, 2007; Connolly et al., 2013; Connolly et al., 2014; Shahraki et al., 2015; Sayeed and Shahin, 2016), have represented tracks using 3D FE models. The two main drawbacks of these models are the large computational time and the large storage capabilities required: Ju and Li (2011) reported 9 days of calculation and a computer memory requirement of $6.5 \mathrm{~GB}$ for a model of $2 \mathrm{~km}$ of track with about 13 million degrees of freedom and 4000 time steps. Aiming at reducing time computation, authors have proposed 2D FE models with modified plane strain (Fernandes et al., 2014) or with modified plane stress condition (Ribeiro, 2012; Paixão et al., 2015), which allows good description of the track geometry but implies approximation regarding the cross section of the track. Even if the model is two dimensional, a track width can be specified to compute stress in layers. To calibrate its value, a 3D computation has to be made in parallel. This methodology leads to approximations since the repartition of stress is not uniform in the width of the track.

Considering the track as invariant in the rail direction, different authors have proposed a coupled Finite Element (FE)-Boundary Element (BE) numerical model in $2.5 \mathrm{D}$ (Yang and Hung, 2001; Yang et al., 2003; François et al., 2010; Alves Costa et al., 2012). These approaches imply approximations on the track geometry since sleepers are discontinuous. As shown by Chebli et al. (2008), this limitation can be bypassed using Floquet transforms and computations on a generic 3D cell, considering track as periodic, as illustrated in Fig. 1. Computation time is then reduced and infinite soil layers can be considered.

Section '3D FEM with Floquet transform' details a methodology for the numerical computation in the frequency domain of 3D periodic models. This methodology is an alternative to Wave Finite Element method (Mace et al., 2005; Collet et al., 2011) used to compute wave propagation in wave guides. Links between the two approaches have been clarified in Balmes et al. (2016). In the field of railway modeling this approach is similar to the one of Chebli et al. (2008), based on the Floquet transform of a "slice" of the track. Outside a clarification of equations, the contribution of the section is a discussion of numerical strategies used to reduce models in the frequency domain and to choose wavenumbers for the spatial Fourier transform.

On a realistic track model, Section 'Numerical application' then uses the proposed methodology to detail the relation between peaks visible in receptance curves and propagating waves in the track.

The main drawback of existing wave domain approaches is that calculations can only be made in the frequency domain. The authors of the present paper have been long developing model reduction techniques for nominally periodic structures which use periodic solutions as starting vectors to build Ritz bases for the generic 3D cell. This concept has been used in Sternchüss (2009) for multi-stage rotors and since 2003 in the development of

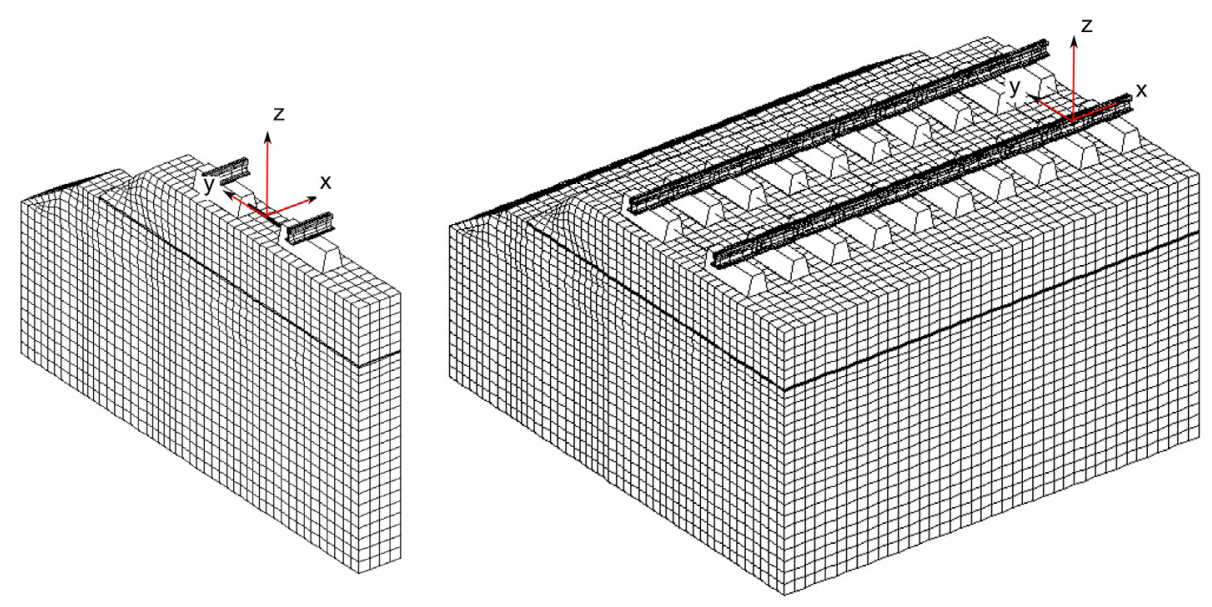

Fig. 1. Track as a periodic structure, the basic cell is on the left. 
the Dynavoie software (Arlaud et al., 2016). Using reduced super-elements for basic cells enables transient analysis, inclusion of non-linear behavior in the vehicle as well as track, or handling of transitions. The numerical method, detailed here, will later be used to provide a reference for the validation that reduced models reproduce the main features of the track dynamics. Hence the objective of this paper to use 3D periodic computations to analyze track dynamic properties in detail.

A drawback of the reduction methodology of Dynavoie is that is has not yet been extended to the treatment of exact or approximate (Komatitsch and Tromp, 2003; Kouroussis et al., 2011; Connolly et al., 2014) representations of Sommerfeld conditions. Since the end objective of the present work is to use reduced 3D models in the time domain, artificial fixed or free boundaries are thus introduced in the soil below and away from the track and the impact of such boundaries on the responses of interest is analyzed. Soil depth is particular analyzed, showing that the presence of bedrock or stiffer layers in depth allows the use of a finite depth. Soil width is also addressed in the last section and shown to have a minor impact in the considered case, provided a sufficiently wide platform is modeled.

Finally, in Section 'Experiments and modeling with different track designs', the model is confronted to experiments conducted on a French High Speed Line area known to present different substructure designs. The experiments are first used to highlight the influence of substructure properties in the receptance curves. The influence of model parameters is discussed and the impact of substructure designs on experimental receptance curves is interpreted.

\section{D FEM with Floquet transform}

In order to compute the receptance response and analyze the associated motion within the track, direct FEM computations in the frequency domain would be too long due to models with millions of degree of freedom and the need to compute thousands of frequencies. Starting from a 3D FEM model of a slice, taking into account that the track geometry is periodic allows the use of a spatial Fourier transform leading to Floquet transform theory as used in Chebli et al. (2008). For each spatial wavelength, the frequency range being known, modal models can be used to compute many frequency points. The section thus details the proposed numerical procedure and associated numerical choices.

\section{Direct and inverse Floquet transforms in the spatial domain}

A structure is said spatially periodic when it is composed of geometrically identical cells (labeled "slices" in this paper), generated by a translation on a predefined direction ( $x$ in the following work) from the reference slice. For tracks, as displayed in Fig. 1, the evenly spaced sleepers on which lays the rail define the minimum periodicity of the structure in its development direction. The basic slice width $\Delta x$ is thus the sleeper spacing, $0.6 \mathrm{~m}$ for French HSL.
Using this geometric periodicity, any mechanical field of interest can be represented as series of slices of number $n$ and position $x_{0}$ within the reference slice, that is $u_{n}\left(x_{0}\right)=u\left(x_{0}+n \Delta x\right)$ with $\left.n \in\right]-\infty \infty[$.

For each position in the reference slice the Floquet transform can be computed

$U\left(x_{0}, \kappa_{c x}\right)=\sum_{n=-\infty}^{\infty} u\left(x_{0}+n \Delta x\right) e^{-i \kappa_{c x} n}$,

where $U\left(x_{0}, \kappa_{c x}\right)$ is a complex shape defined on the reference cell.

The conventions used in this work regarding this spatial transform are the following:

- $n_{c x}$ is the wavelength or spatial periodicity in number of cells, so $n_{c x} \in\left[1 \infty\left[\right.\right.$. The physical wavelength $\lambda_{x}$ in length unit is then given by $\lambda_{x}=n_{c x} \times \Delta x$.

- The discrete wavenumber $\kappa_{c x}$ in $\mathrm{rad} /$ numberofcells is then given by $\kappa_{c x}=2 \pi / n_{c x}$, so $\kappa_{c x} \in[02 \pi]$.

The inverse Floquet transform allows recovery of the physical field $u$ based on its wave domain values $U$

$u\left(x_{0}+n \Delta x\right)=\frac{1}{2 \pi} \int_{0}^{2 \pi} U\left(x_{0}, \kappa_{c x}\right) e^{i \kappa_{c x} n} d \kappa_{c x}$.

It may be useful to note that the Floquet transform corresponds to the periodic function in the wave domain associated with a Fourier series whose coefficients are the responses at periodically spaced locations. Responses in the frequency / wavenumber domain will thus, in later sections, be interpreted as 2D Fourier transforms of responses sampled in the time / space domain.

A key property of periodic systems, see for example (Sternchüss, 2009), is that for excitations at a given wavelength, described as a field on the nominal cell $U\left(x_{0}\right)$ associated with a single wavenumber $\kappa_{c x}$, the only response occurs at the same wavelength $\kappa_{c x}$ provided that the geometry and model properties are strictly periodic. A large FEM problem with repeated slices can thus be decomposed in a series of independent problems for single wavenumbers, which correspond to periodic solutions.

For a solution with a single wavenumber $\kappa_{c x}$, the field is simply equal to

$u\left(x_{0}+n \Delta x\right)=\operatorname{Re}\left(U\left(x_{0}, \kappa_{c x}\right) e^{i \kappa_{c x} n}\right)$,

which will be used to compute the periodic solutions in the next section.

As $\kappa_{c x}$ is continuous in the $[02 \pi]$ interval, numerical implementations must make a choice regarding which values of $\kappa_{c x}$ to consider and how to build the numerical approximation of the inverse transform. Since the integral is a linear function, its result can be expressed as a linear operator

$$
\left\{u\left(x_{0}+n \Delta x\right)\right\}=\left[E_{n k}\right]\left\{\begin{array}{l}
\operatorname{Re}\left(U\left(x_{0}, \kappa_{c x}\right)\right) \\
\operatorname{Im}\left(U\left(x_{0}, \kappa_{c x}\right)\right)
\end{array}\right\}
$$

Matrix $[E]$ has as many rows as cells where the displacement is to be computed and as many columns as wavenumbers chosen, with the convention $\kappa_{0}=0$ and the last one equal to $2 \pi$. This matrix is here defined as 


$$
\begin{aligned}
& E_{n(2 k-1)}=\cos \left(n \kappa_{k}\right) \frac{\left[\left(\kappa_{k+1}-\kappa_{k}\right)+\left(\kappa_{k}-\kappa_{k-1}\right)\right]}{2 \pi} \\
& E_{n(2 k)}=-\sin \left(n \kappa_{k}\right) \frac{\left[\left(\kappa_{k+1}-\kappa_{k}\right)+\left(\kappa_{k}-\kappa_{k-1}\right)\right]}{2 \pi}
\end{aligned}
$$

which corresponds to a simple integration rule assuming $U\left(x_{0}, \kappa_{c x}\right)$ constant over the $\left[\left(\kappa_{k}+\kappa_{k-1}\right) / 2\left(\kappa_{k+1}+\kappa_{k}\right) / 2\right]$ interval. The choice of $\kappa_{c x}$ will be addressed in Section 'Im plementation strategies'.

\section{Periodic FEM computations}

In the case of structures represented as FE models, the continuous displacement in the nominal cell $u\left(x_{0}\right)$ is discretised and replaced by a vector $\{q\}$ of Degrees Of Freedom (DOF) values.

To ensure the displacement continuity between adjacent periodic cells, a continuity condition must be introduced. The displacement on the left boundary of one cell has to be equal to the one of the preceding cell right edge, thus $\left\{q_{\text {left }}(n \Delta x)\right\}=\left\{q_{\text {right }}((n-1) \Delta x)\right\}$. Following the definition given in the previous section, $\left\{q_{n}\right\}$ represents all the displacements at the DOF of the cell number $n$. For each cell, the observation matrices $\left[c_{l}\right]$ and $\left[c_{r}\right]$ can then be defined to extract on the whole DOFs the ones corresponding to left and right boundaries respectively. These matrices are the same for all cells if the domain is meshed regularly.

For a periodic response associated with a single wavenumber, taking into account Eq. (3), the continuity condition can be written as $\left[c_{l}\right]\left\{Q\left(\kappa_{c x}\right)\right\}=\left[c_{l}\right]\left\{Q\left(\kappa_{c x}\right)\right\} e^{-2 i \kappa_{c x}}$ which, differentiating real and imaginary parts, leads to

$$
\left[C\left(\kappa_{c x}\right)\right]\left\{\begin{array}{l}
\operatorname{Re}\left(Q\left(\kappa_{c x}\right)\right) \\
\operatorname{Im}\left(Q\left(\kappa_{c x}\right)\right)
\end{array}\right\}=0
$$

with

$$
\left[C\left(\kappa_{c x}\right)\right]=\left[\begin{array}{ll}
{\left[c_{l}\right]-\cos \left(\kappa_{c x}\right)\left[c_{r}\right]} & -\sin \left(\kappa_{c x}\right)\left[c_{r}\right] \\
\sin \left(\kappa_{c x}\right)\left[c_{r}\right] & {\left[c_{l}\right]-\cos \left(\kappa_{c x}\right)\left[c_{r}\right]}
\end{array}\right] .
$$

For an external force $\{f\}$ applied to the system, $s$ being the Laplace variable, the first step is to compute the Floquet (spatial Fourier) transform of the load $F\left(\kappa_{c x}, s\right)$. Then the equations of motion, which are known to be decoupled for each wavenumber, take the frequency domain form

$$
[Z(s)]\left\{Q\left(\kappa_{c x}, s\right)\right\}=\left\{F\left(\kappa_{c x}, s\right)\right\},
$$

where $Z(s)=M s^{2}+K$ is the dynamic stiffness matrix. This matrix contains mass $M$ as well as stiffness and damping in the matrix $K$. The matrix $K$ can take into account hysteretic damping (constant imaginary part of $K$ ) or viscoelastic contributions (frequency and temperature dependent $K(s)$ ), see (Balmes, 2004-2013). In the work presented in this paper, only hysteretic damping is taken into account.

Since the frequency response can be complex in the spatial domain, it is necessary to distinguish real and imaginary parts of the spatial transform. The equations actually solved are thus

$$
\left[\begin{array}{ll}
Z(s) & 0 \\
0 & Z(s)
\end{array}\right]\left\{\begin{array}{l}
\operatorname{Re}\left(\left\{Q\left(\kappa_{c x}, s\right)\right\}\right) \\
\operatorname{Im}\left(\left\{Q\left(\kappa_{c x}, s\right)\right\}\right)
\end{array}\right\}=\left\{\begin{array}{l}
\operatorname{Re}\left(F\left(\kappa_{c x}, s\right)\right) \\
\operatorname{Im}\left(F\left(\kappa_{c x}, s\right)\right)
\end{array}\right\},
$$

with (6) verified.
Solution of a linear system equation (8) with constraint (6) is traditionally done either by penalty method, Lagrange multipliers or elimination method (Bathe, 2006). The last solution is chosen here. The continuity condition is thus taken into account by first seeking a basis $T$ of $\operatorname{ker}\left(\left[C\left(\kappa_{c x}\right)\right]\right)$. Then this basis is used to find the solution of the constrained problem

$$
\left([T]^{T}\left[Z\left(\kappa_{c x}, S\right)\right][T]\right)\left\{Q\left(\kappa_{c x}, S\right)\right\}=[T]^{T}\left\{F\left(\kappa_{c x}, S\right)\right\} .
$$

Solving directly this problem can be fairly long as it requires inversion of the constrained dynamic stiffness $T^{T} Z(s) T$ at each desired frequency. Modal synthesis methods are thus preferred here. The first step is thus to compute periodic modes as solution of the eigenvalue problem

$$
\left(T^{T}\left[K-\omega_{j}^{2} M\right] T\right)\left\{\phi_{j}\left(\kappa_{c x}\right)\right\}=0 .
$$

Then, first order correction for the imaginary part of the dynamic stiffness is used to obtain a reduced model for which the frequency response can be computed efficiently (Balmes and Germes, 2004).

\section{Implementation strategies}

The proposed implementation combines two levels of reduction.

First, for each wavenumber, a reduced model is computed. The size of this model is associated with the bandwidth selected by the user. All modes within the target bandwidth are kept and first order correction for damping is computed for each. A by-product of this computation is the dispersion diagram showing the evolution of modal frequencies with wavenumber.

A sample dispersion diagram, computed using 20 wavenumbers is shown in Fig. 2(a). The corresponding structure displayed on Fig. 2(b) is composed of rail, pads, monobloc sleepers, resting on $75 \mathrm{~cm}$ of ballast. A beam element used for the rail is rigidly connected to linear elastic volumes used for the pad, sleeper and ballast. The properties assumed for the ballast layer are Young modulus $80 \mathrm{MPa}$, Poisson ratio 0.3 , loss factor 0.06 and density $1900 \mathrm{~kg} / \mathrm{m}^{3}$. The dispersion diagram clearly indicates that at a given wavenumber, only a few modes exist. The use of mode synthesis methods is thus quite appropriate.

While a deeper analysis of the dispersion diagram is useful and will be proposed in Section 'Resonances and peaks of the receptance curve', its shape was used to motivate the strategy to select the wavenumbers for inverse transform Eq. (4). This is the second step of time computation reduction. Whereas in classical discrete Fourier transform wavenumbers are chosen evenly spaced in the $\left[\begin{array}{ll}0 & 2 \pi\end{array}\right]$ interval, the use of irregular spacing is proposed here. For small wavenumbers, the frequencies evolve rapidly in the dispersion diagram, so that close spacing is needed. At higher wavenumbers the evolution is slower and the wavenumber spacing can be decreased as shown by markers in Fig. 2.

To ensure that this strategy of selection of wavenumbers is appropriate, a comparison is made in Fig. 3 with the classical discrete Fourier transform with evenly dis- 


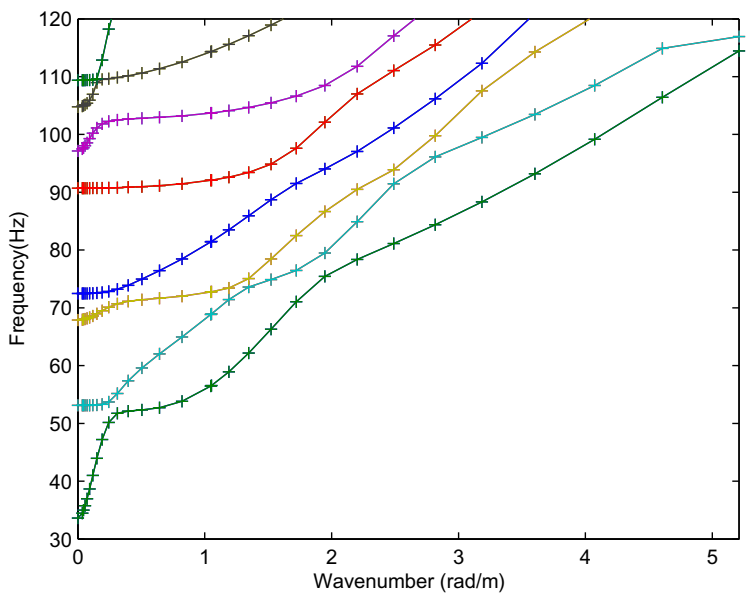

(a)

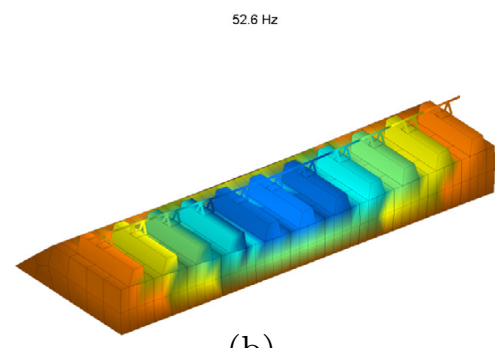

(b)

Fig. 2. Dispersion diagram for a simple test case.

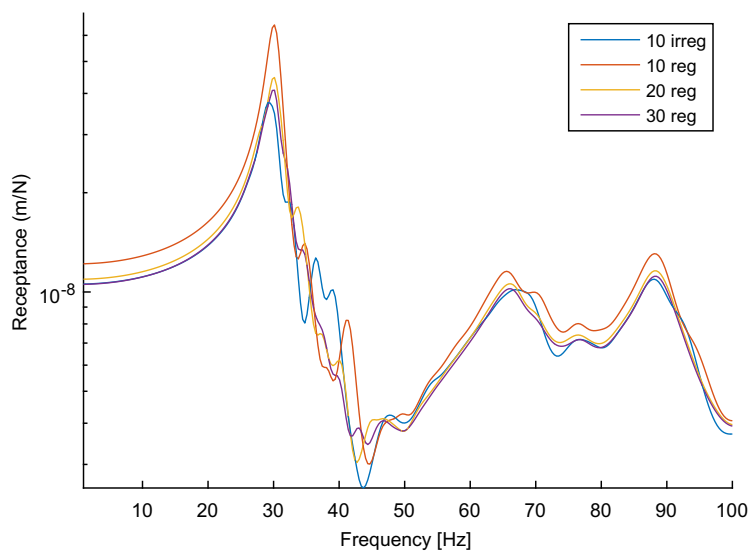

Fig. 3. Comparison of receptance curves computed with 10 (in blue) unevenly distributed wavenumbers and 10, 20 and 30 (respectively in red, yellow and purple) evenly distributed wavenumbers. (For interpretation of the references to colour in this figure caption, the reader is referred to the web version of this article.)

tributed wavenumbers. The curves are the simulated response in displacement of the basic structure described above to a vertical impact load on the top of the rail. In blue is represented the response with 10 wavenumbers unevenly spaced. It is compared with the response computed with 10, 20 and 30 evenly spaced wavenumbers, presented in the same graph. Increasing the number of chosen wavenumbers evenly spaced leads to a receptance curve closer to the one computed with 10 unevenly spaced $\kappa$. This shows that choosing less wavenumbers if correctly spaced can lead to a good precision at a much lower calculation time.

This conclusion is also valid for more complex structures such as the one described and studied in the following section, see Fig. 5.

\section{Numerical application}

Having introduced a general methodology to compute responses of large 3D FEM in the frequency domain, this section first analyzes the response associated with the receptance test in the frequency, wavenumber and spatial domains. Then, as this work is a first step for the development of reduced FE models, limitations associated with the bounded nature of FE models regarding the depth of soil considered is detailed. In particular, no specific boundary condition for frequency domain calculation are considered. The purpose here is to show that even with this limitation, it is possible to correctly model the behavior inside the track, provided considering a model with a platform sufficiently wide.

\section{Model description}

The proposed test case is that of the high speed ballasted track presented in Costad'Aguiar et al. (2015). All layers, sleepers and rail are considered as linear elastic with properties summarized in Table 1, and geometry is recalled in Fig. 9 (in this case the additional width is $2 \mathrm{~m}$ and the soil depth $5 \mathrm{~m}$ ). All elements are volumes.

Railpad is the physical link between rail and sleeper. It is also modeled using finite elements. A specific rule is used to build the equivalent vertical modulus ( $A$ being the horizontal section of pad, hs the pad thickness and $k$ its stiffness) is

$E=\frac{k h s(1+v)(1-2 v)}{A(1-v)}$

which corresponds to the vertical stiffness of a volume with sliding edges (Oregui et al., 2014). The stiffness of pads is frequency-dependent and load dependent (Maes et al., 2006). As stiffness increases with frequency, an interpolation law is used to implement varying stiffness in this component. At $0 \mathrm{~Hz}$ railpad stiffness $\mathrm{k}$ is set to $60 \mathrm{kN} / \mathrm{mm}$ and at $500 \mathrm{~Hz}$ to $400 \mathrm{kN} / \mathrm{mm}$. These values are identified on internal specification tests for pads, and the value at $500 \mathrm{~Hz}$ has been verified using the resonance of the rail

Table 1

Material properties.

\begin{tabular}{lllll}
\hline & $E(\mathrm{GPa})$ & $v$ & $\rho\left(\mathrm{kg} / \mathrm{m}^{3}\right)$ & $\eta$ \\
\hline Rail & 210 & 0.285 & 7800 & 0.01 \\
Sleeper & 30 & 0.25 & 2400 & 0 \\
Ballast & 0.200 & 0.3 & 1700 & 0.1 \\
Non treated subballast & 0.180 & 0.35 & 2135 & 0.04 \\
Form layer & 0.200 & 0.3 & 1800 & 0.04 \\
Soil layer & 0.075 & 0.2 & 1800 & 0.04 \\
\hline
\end{tabular}


over the sleepers in the receptance test (even though this is not detailed). A parameter is also introduced to model the rail rotation controlled by the fastening system, its value is set to $10 \%$ of the value calculated for an isotropic pad in compression. The shear modulus in the ballast layer is also adjusted to $5 \mathrm{MPa}$.

For the application of a hammer impact at the top of the rail, representative of receptance tests, Eq. (8) is solved for sixty wavenumbers, using a discretisation of $0.5 \mathrm{~Hz}$ in frequency for the periodic modes calculation. The spacing of wavenumbers is uneven using a log spacing with thirty values between 0 and 1 , and a log spacing for another set of thirty values between 1 and $2 \pi$. The influence of this choice is discussed in the Section 'Influence of FE representation of soil'.

Receptance is displayed in Fig. 4. Several peaks appear in the receptance curve, the main one being at $9.7 \mathrm{~Hz}$. Due to the infinite nature of the track, this peak cannot correspond to a modal resonance classically found when analyzing finite structures. Since this is not an obvious result, mechanisms giving birth to the peaks are detailed in Sect ion 'Resonances and peaks of the receptance curve'.

\section{Resonances and peaks of the receptance curve}

This section seeks to illustrate the origin of peaks visible in the receptance curve. From Eq. (1), it appears that the full frequency response is a combination of the periodic responses at specific wavelengths. It can thus be useful to analyze the forced response contributions as a function of wavelength as shown in Fig. 5. In this Figure, the colormap represents the vertical displacement, from blue for no displacement to yellow for high displacement. A horizontal line in Fig. 5 represents the vertical response to a load on the rail with the associated wavelength.

Fig. 6 represents sample curves for wavelength equal to 58 and $300 \Delta x$. In this Figure, vertical dotted lines represent the frequencies of periodic modes solution of Eq. (10). As expected these frequencies generate modal resonances in the periodic forced response.

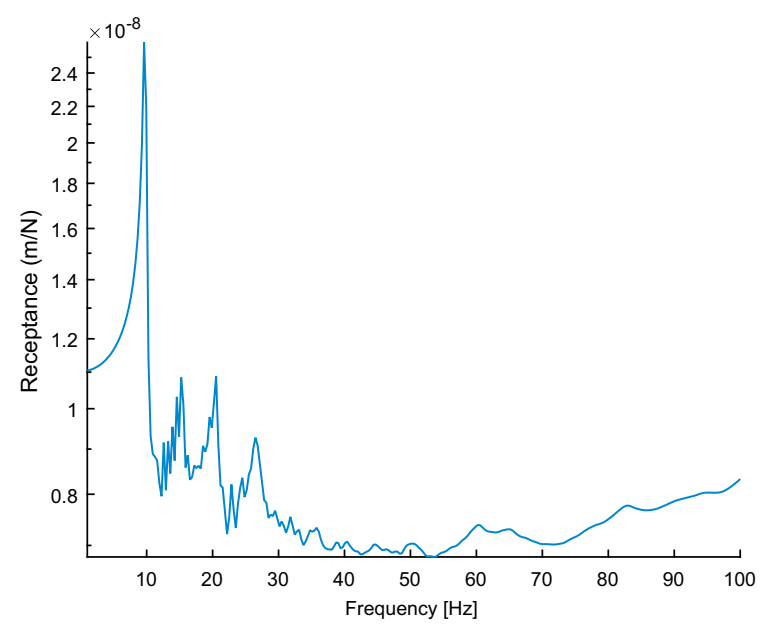

Fig. 4. Receptance curve computed for a high speed track design.

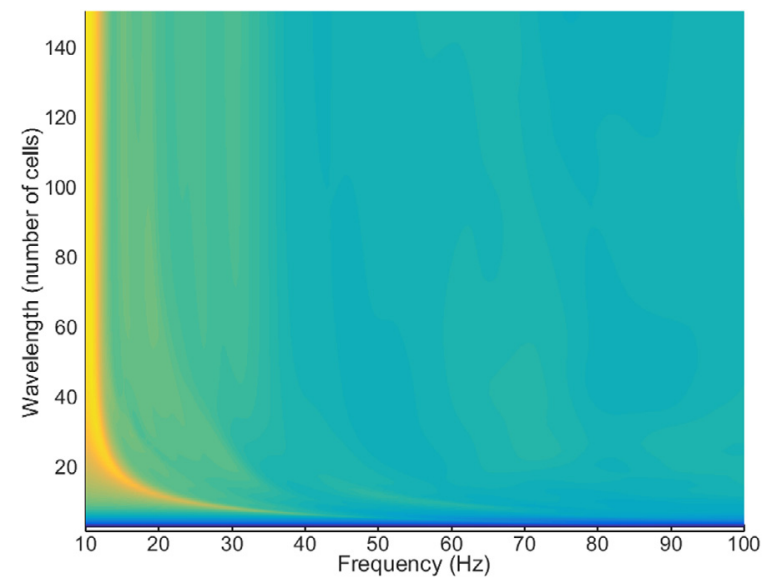

Fig. 5. Decomposition of receptance in frequency and wavenumber domains. Colour is proportional to the vertical displacement from yellow (high displacement) to dark blue (no displacement). (For interpretation of the references to colour in this figure caption, the reader is referred to the web version of this article.)

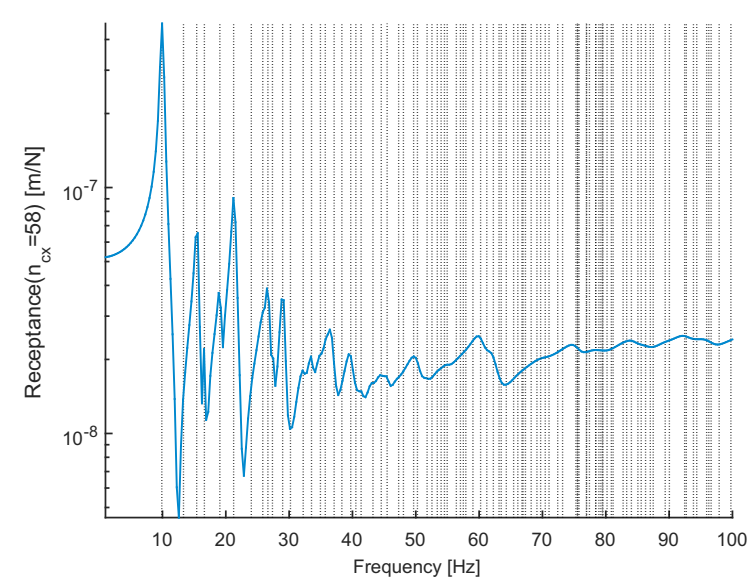

(a) $n_{c x}=58$ number of slices

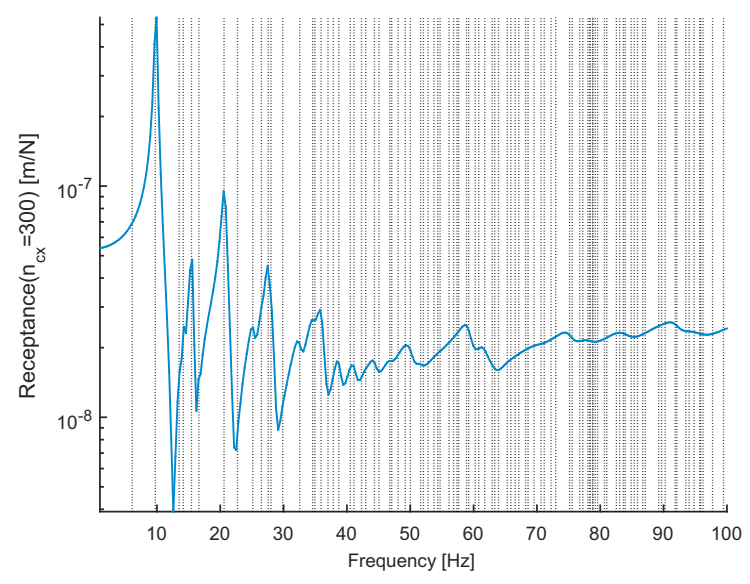

(b) $n_{c x}=300$ number of slices

Fig. 6. Vertical response to an impact for two wavelengths. 
For each modal resonance, it is possible to visualize modes as illustrated in Fig. 7, where it appears that similar motion occurs within the track with a minor shift in frequency for the two wavelengths (at $10 \mathrm{~Hz}$ for a wavelength of 58 slices and at $9.9 \mathrm{~Hz}$ for a wavelength of 300 slices).

In the global receptance of Fig. 4, however, only a few main peaks are visible and understanding their origin is useful. Comparing the full response of Fig. 4 and its components by wavelength in Fig. 5 reveals that peaks will appear in the global receptance when displacement is high for several wavelengths at the same frequency (vertical yellow lines). This occurs when the dispersion diagram shows nearly vertical lines: frequencies that do not change with wavelength.

The forced response at $9.7 \mathrm{~Hz}$ corresponding to the main receptance peak shown in Fig. 8 has a section deformation that is very similar to the periodic modes shown in Fig. 7. But, as it corresponds to the combination of multiple-wavelengths, it clearly has a finite extent localized around the impact point.

The main conclusion is that the peaks of the receptance curve result from many periodic modes and do not correspond to an eigenmode of the track. Furthermore, peaks are associated with slow variations of modal frequencies that are easily seen in the dispersion diagram. The associated deformations in the track and platform were visualized and, in Section 'Experiments and modelling with different track designs', will be shown to help in understanding the impact of substructure changes on the dynamic behavior of the track.

\section{Influence of FE representation of soil}

Using the spatial Fourier transforms gives the ability to compute the frequency response of very large FEM. With the objective of verifying reduced FE models used in the

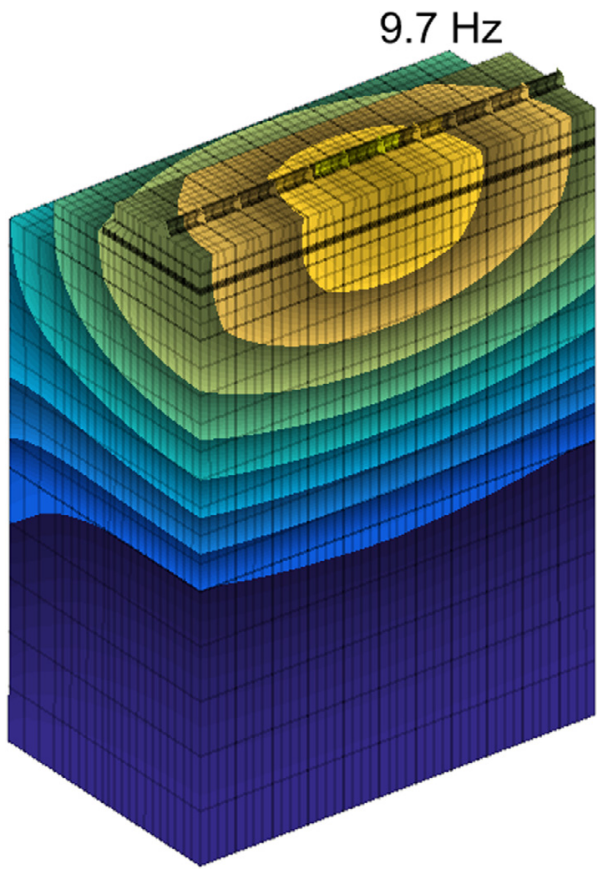

Fig. 8. Deformation corresponding to the main peak of the receptance curve (yellow is high displacement, to dark blue no displacement). (For interpretation of the references to colour in this figure caption, the reader is referred to the web version of this article.)

Dynavoie time domain simulations (Arlaud et al., 2015), in this section the impact of the section geometry and its properties will be analyzed.

The first effect to be quantified that of boundaries. Indeed, in real tracks, waves can propagate in the soil both laterally and vertically, whereas in FE models they reflect on artificial boundaries unless specific models, such

$10.0 \mathrm{~Hz}$ load 16, ncx58.0802-ak1-kx0.180302

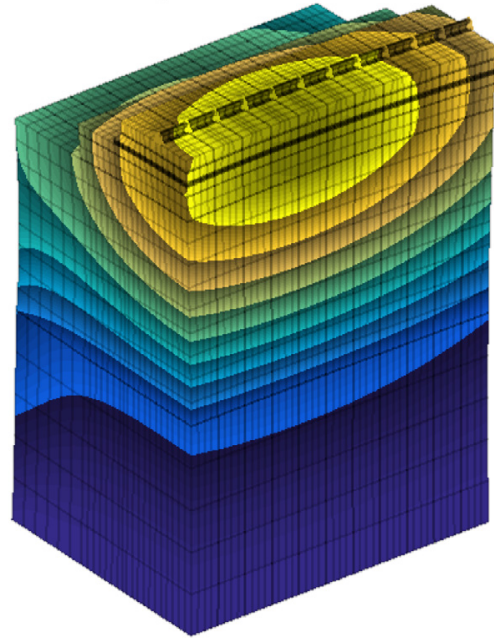

$9.9 \mathrm{~Hz}$ load 2, ncx300-ak1-kx0.0349066

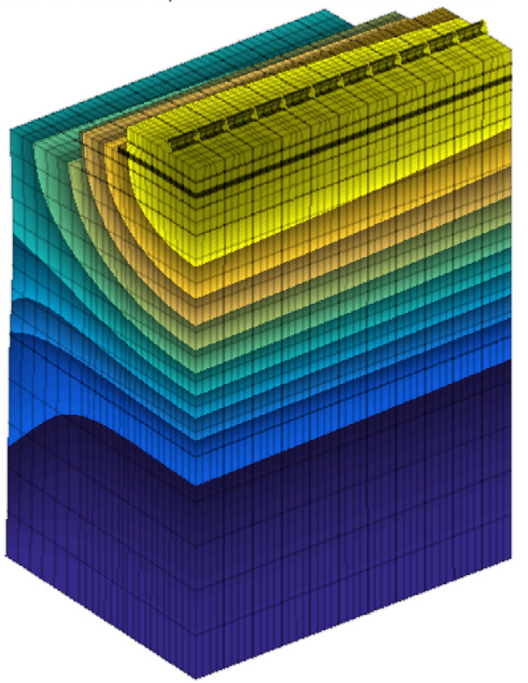

(a) $n_{c x}=58$ number of slices

(b) $n_{c x}=300$ number of slices

Fig. 7. Two periodic modes for ballasted track corresponding to a resonance in the receptance curve at a given wavelengths (Fig. 6). 
as boundary elements or perfectly matched layers (Komatitsch and Tromp, 2003), are introduced. As such developments are not easily combined with model reduction and time domain simulations, which are the end objective here, this section analyzes the effect of classical FEM boundaries when modeling soil. The varying parameter studied in this part is soil depth, as shown in Fig. 9.

Fig. 10 addresses the impact of soil depth, considering an additional width of $2 \mathrm{~m}$ as shown in Fig. 9. For constant properties, the principal resonance peak always moves to lower frequencies with soil depth increase. Depth of soil thus clearly has a major impact, so that an accurate modeling of soil is crucial to get correct result. To do so, a refinement of the soil model is proposed.

Modeling soil as an uniform elastic layer is not realistic, as physically there is a consolidation of granular materials under pressure (Biarez and Hicher, 1994), and pressure increases with depth in the soil layer. To take this phenomenon into account, the model integrates a variable modulus gradually increasing with pressure as

$E=E_{0}\left(\frac{P}{P_{0}}\right)^{n}$.

In the soil layer, the elastic modulus follows Eq. (12) with $E_{0}$ as a fitting parameter, to adjust the Young modulus of the layer at a known value at a chosen depth. $P_{0}$ is set equal to atmospheric pressure. Then, $P=P_{\text {sup }}+P_{\text {layer }}$ with $P_{\text {sup }}$ the pressure at the top of the identified layer (induced by upper layers), and $P_{\text {layer }}$ the pressure induced by the current layer. $P_{\text {layer }}=\frac{\sigma_{z z}+2 \sigma_{y y}}{3}$ and $\sigma_{y y}=K_{0} \sigma_{y y}$ with $K_{0}$ the earth

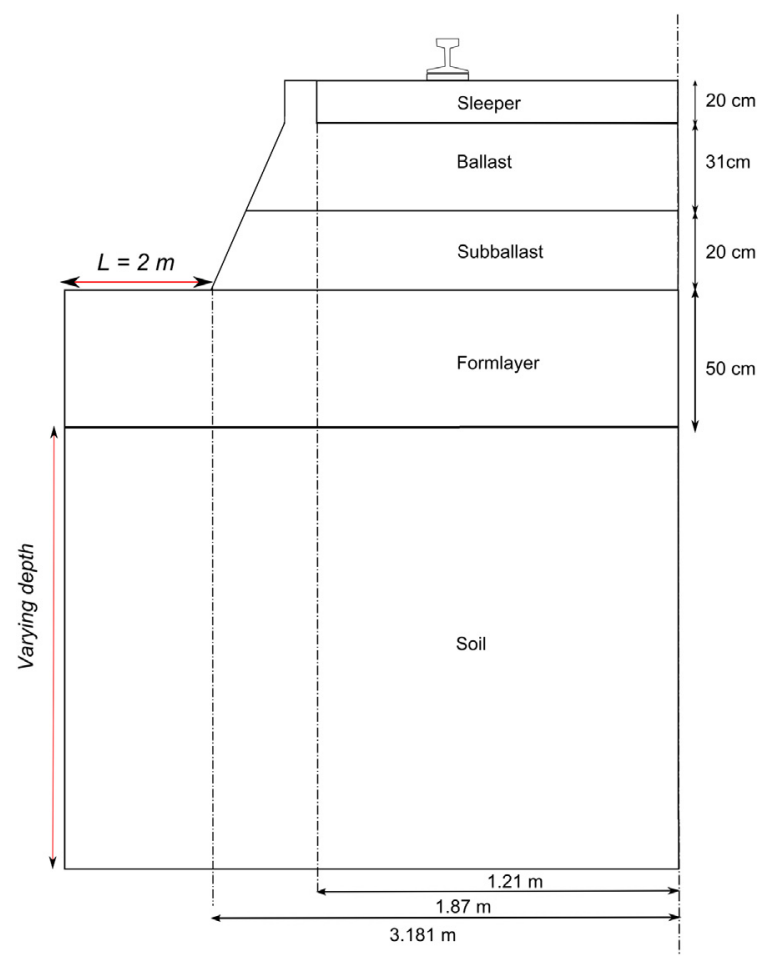

Fig. 9. Schematic representation of the track section and varying soil depth to study the influence of the bounded soil modeling.

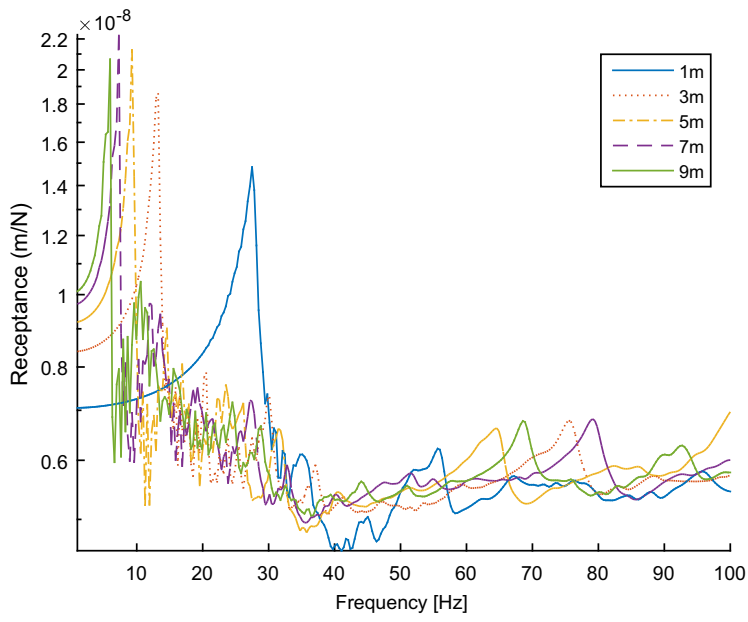

Fig. 10. Comparison of receptance curve for several soil depth.

pressure coefficient. In the following work, the value $K_{0}=0.5$ is chosen, which leads to

$E=E_{0}\left(\frac{P_{\text {sup }}+\rho g z}{P_{0}}\right)^{n}$.

$\sigma_{z z}$ is the sum of the pressure exerted by the upper layers and by the gravity in the current layer. Finally, the value of exponent $n$ depends on the nature of soil. For a sand, the value is close to 0.5 , for clay, it is set between 0.7 and 0.9 (Biarez and Hicher, 1994).

For uniform elastic modulus and gradient elastic modulus four receptances are computed using models with $3 \mathrm{~m}$, $5 \mathrm{~m}, 7 \mathrm{~m}$ and $9 \mathrm{~m}$ soil depth. Fig. 11 shows the evolution of the frequency position of the main peak of receptance with increasing soil depth. In both cases (uniform and gradient elastic modulus), the depth of soil considered in the model influences the result. Considering gradient properties in soil changes the frequency of receptance main peak. Fig. 11 shows that this frequency does not converge, even

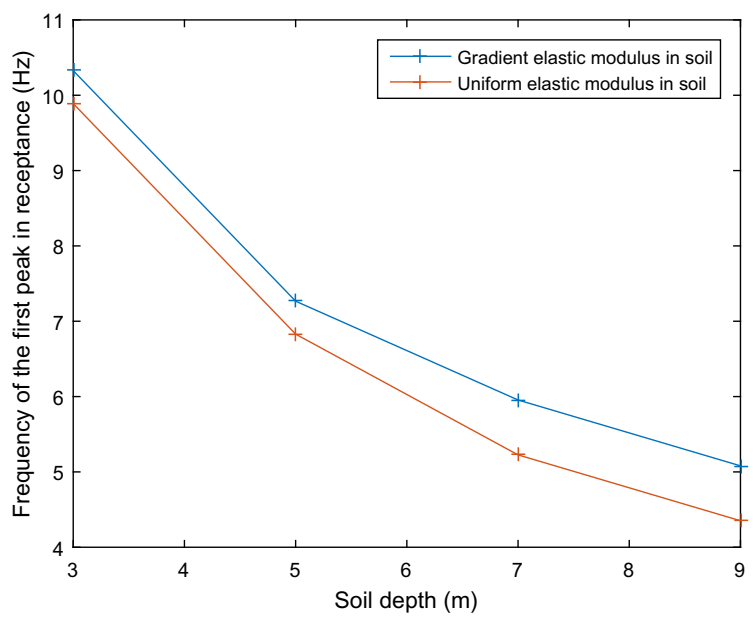

Fig. 11. Evolutions of the frequency position of the main peak of receptance with uniform or gradient elastic modulus in soil. 
with gradient properties. This can be a factor limiting our ability to correctly model deep soft soil layers using FEM. However, in real tracks, the presence of a stiffer layer or bedrock is quite common. In this case, as shown in Sectio $\mathrm{n}$ 'Comparison between measurement and numerical model' combination of gradient properties in the soft part and rigid boundaries for the stiffer part is a realistic approximation of real cases. Then, knowledge of geological properties of the site of interest is obviously indispensable for accurate predictions as shown in Section 'Comparison between measurement and numerical model'.

\section{Experiments and modeling with different track designs}

A study on a French HSL is presented in this section. In this specific area, receptance tests results are detailed and the effect of substructure changes in the receptance curve is particularly highlighted. Then, the chosen area is modeled using the numerical method previously introduced. Comparison between experiments and modeling is proposed. Finally, simulations are used as a complement, in order to give explanations to phenomena observed on experimental results.

\section{Test site}

Receptance tests were performed in-situ at the Chauconin test site on the French East European HSL between Paris and Strasbourg. As this line is currently operated, tests were performed during night interruptions.

This area presents a transition between ballasted and slab track as displayed in Fig. 12. Transition zones are known to present specific behavior compared to other areas of track (Shan et al., 2013; Mishra et al., 2014; Momoya et al., 2015). In Chauconin test site, that four track designs are in close proximity, the properties are described in Costad'Aguiar et al. (2015). The objective of this section is to assess the impact of substructure properties changes in the global track response. The chosen transition presents at least three changes in the substructure for a fixed superstructure (sleepers, pads and rail). The slab track, adapted from STEDEF design, is not studied in this paper.

Measurements were performed in the following three different areas:

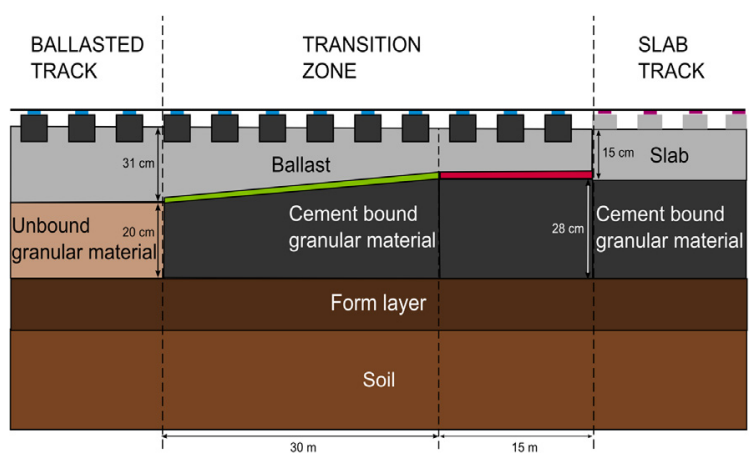

Fig. 12. Description of Chauconin test site (adapted from Costad'Aguiar et al., 2015).
- The ballasted track: this area presents the properties of a conventional high speed design. The capping layer is made of compacted granular material.

- The transition zone with mat 2: this area provides the transition of geometry for the substructure between ballasted track and slab track as displayed in Fig. 12. The thickness of the ballast layer is progressively reduced in order to match the slab track profile. In the substructure, the compacted standard granular material layer is replaced by cement bound granular material, designed to support the slab in the ballastless area. Between ballast and subgrade a polyurethane mat is introduced to provide the stiffness transition between slab track and ballasted track.

- The transition zone with mat 1: this area has the same characteristics as the first part of the transition, except for the ballast mat which has different stiffness properties. This one was chosen softer than in the previous area to progressively reach the slab track stiffness.

\section{Measurement setup}

A set of measurements was performed on each one of these areas. 8 sensors are used, 3 on sleepers and 5 on the top of the rail as displayed in Fig. 13. Three points of impacts were specified, both on and between sleepers.

Characteristics of the measurement system are summarized in Table 2. The sampling frequency is $4096 \mathrm{~Hz}$ and

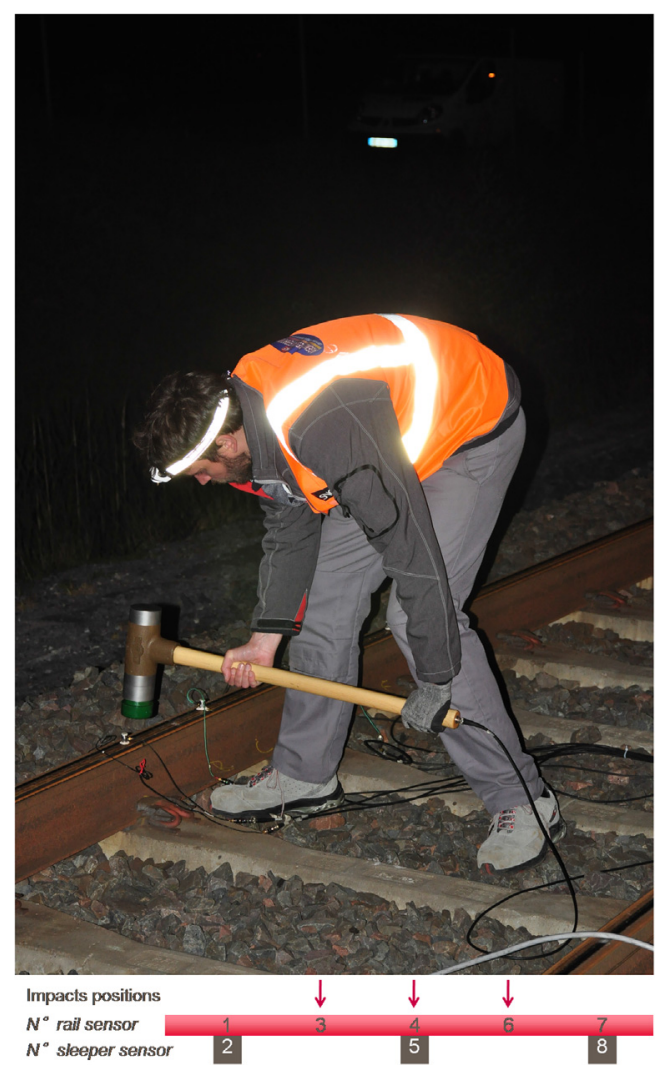

Fig. 13. Experimental setup for receptance tests in Chauconin transition zone test site. 
Table 2

Measurement system properties.

\begin{tabular}{lll}
\hline & Brand & Type \\
\hline Data acquisition software & B\&K & PULSE Labshop v17 \\
Data acquisition hardware & B\&K & LAN-Xi \\
Accelerometers & B\&K & 4513 \\
& DJB & A/120/V \\
Impact hammer & B\&K & 8050 \\
Accelerometer calibrator & B\&K & 4294 \\
\hline
\end{tabular}

the frequency step is $0.5 \mathrm{~Hz}$. An anti aliasing filter is included in the chosen data acquisition hardware The hammer weight is $5.440 \mathrm{~kg}$. The hammer is dropped vertically at the middle of the rail head, as close as possible to the sensor (see Fig. 13).

An example of the load impact on rail and the corresponding acceleration in the time domain is presented in Fig. 14.

The definition of the receptance $H$, given by Man (2002), is the transfer function between the displacement of the rail and the force applied. In the present case, the measured field is acceleration and not displacement, so accelerance is determined:

$H_{a F}(f)^{2}=\frac{S_{a F}(f)}{S_{F F}(f)}$

where $H_{a F}$ is the track accelerance, $S_{a F}$ crossspectrum between the acceleration and the force, $S_{F F}$ autospectrum of applied force.

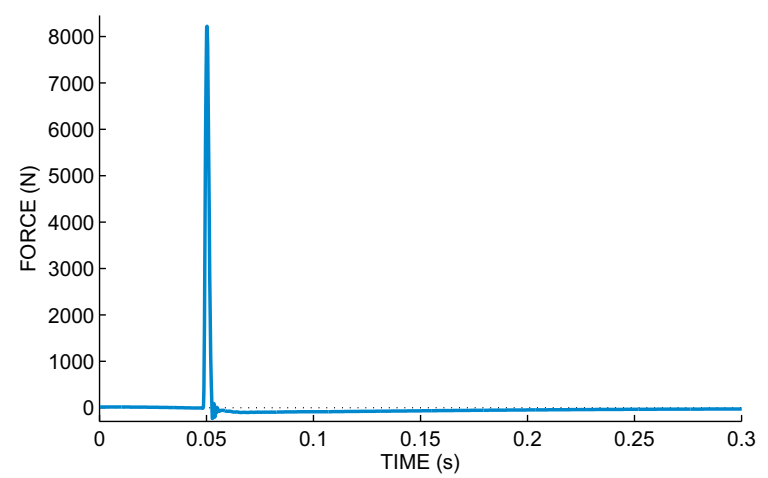

(a) Force

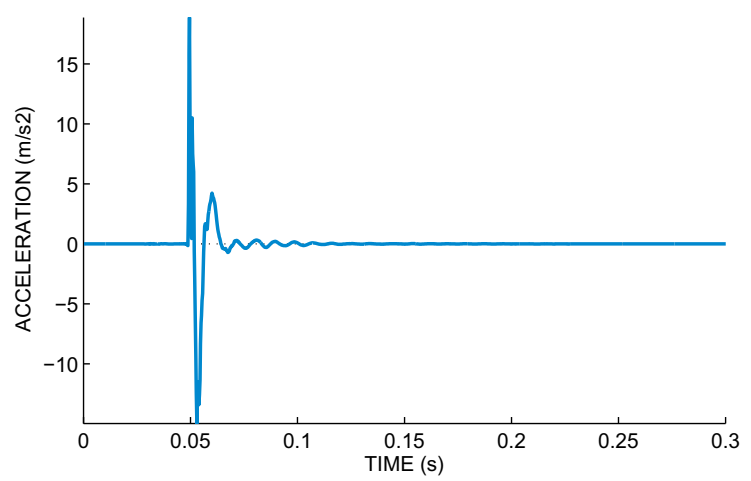

(b) Acceleration

Fig. 14. Example of time impacts for force and acceleration on the top of the rail.
The coherence is also computed as

$C_{a F}(f)^{2}=\frac{\left|S_{a F}(f)\right|^{2}}{S_{F F}(f) S_{a a}(f)}$

A minimum of ten hammer impacts were performed at each chosen point, and the coherence was checked in real time (if it is inferior at 0.9 , the impact was rejected and another one was performed). A rectangular window is applied to force and acceleration signals and this is sufficient since signals decay to zero. Frequency domain double integration is then performed on accelerance to get results in terms of displacement.

\section{Results}

The results of experiments carried on the different areas are displayed in Fig. 15. Each response is an average over ten hammer impacts at the same point for the direct receptance (the point where the displacement is measured is the same as the point of loading). The coherence corresponding to these receptance curves is higher than 0.99 for frequencies between 10 and $100 \mathrm{~Hz}$, showing very good repeatability. The values below $10 \mathrm{~Hz}$ are unreliable due to insufficient acceleration.

In the figure, impacts over multiple sleepers are overlaid to give an indication of variability. For the transition zone with mat 1 , there is a $20 \%$ variation between the softer measured receptance curve and the stiffer one ; for the transition zone with mat 2 , this variation is of $10 \%$ and finally, on the ballasted track, where two campaigns where made in a 6 month interval, the variation reaches $80 \%$. Despite these variations, the global shape of receptance curve clearly depends on the area considered. For further analysis, focus will be on the global shape of the responses and not on their exact amplitude.

The changes in the substructure are clearly visible: the areas of ballasted track with mats are more flexible at low frequencies than the area with no mat. On the contrary, for frequencies higher than $40 \mathrm{~Hz}$, areas with mats are stiffer than the ballasted track. The change of mat is also clearly visible. As it was stated by Costad'Aguiar et al. (2015), the stiffness of mat 1 is between 0.022 and $0.037 \mathrm{~N} / \mathrm{mm}^{3}$ and the one of the mat 2 is between 0.031 and $0.051 \mathrm{~N} / \mathrm{mm}^{3}$. In the experimental results, the part of the transition with the mat 2 has for every frequency a higher flexibility than the transition zone with the mat 1 . This difference is only due to the substructure as the superstructure in the two areas is strictly the same.

It is thus confirmed that the receptance is characteristic of the flexibility of the track and that the impact of substructure changes is sufficient to be clearly visible and thus used as a non-intrusive diagnostic tool. The use of a model will however be necessary to really understand the role of various layers.

Quasi-static stiffness measurements using EMW measurement system (Sodati, 2007; Wang et al., 2016) were performed in this area and are presented in this paper (Costad'Aguiar et al., 2015). A summary of the results is proposed in Table 3. As EMW is a quasi-static measurement of the deflection of the rail, the changes should corre- 


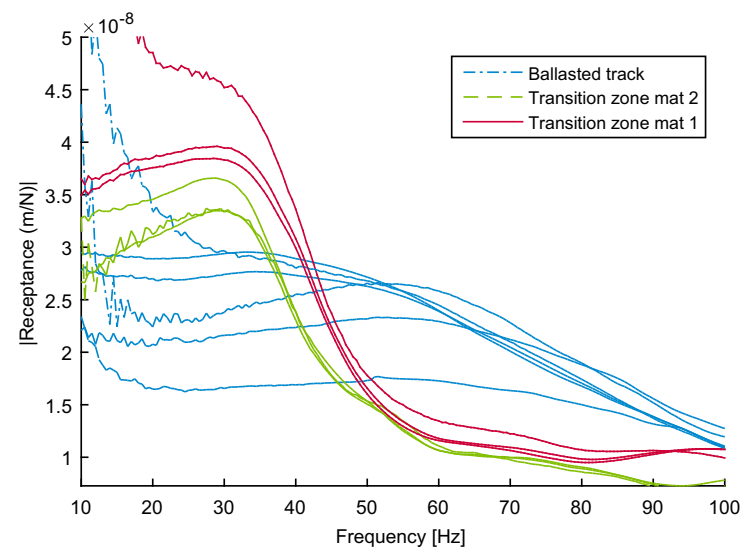

(a) Receptance

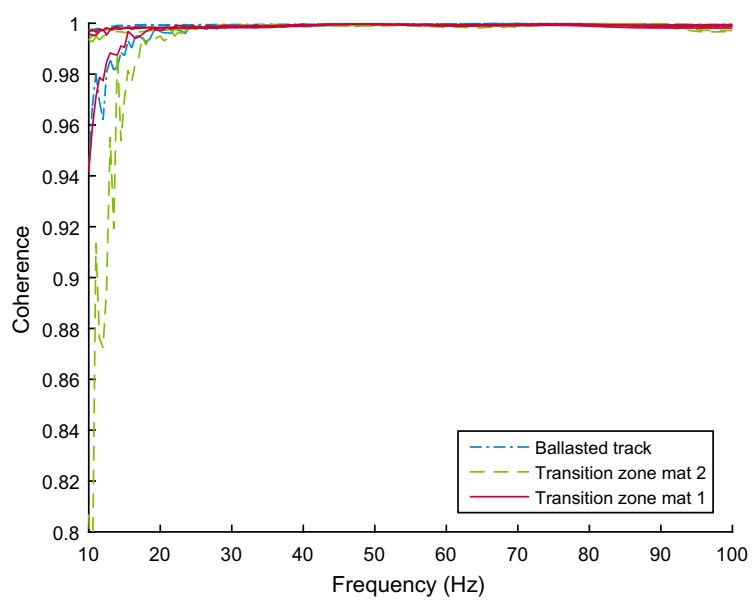

(b) Receptance

Fig. 15. Direct receptances measured on ballasted track (in blue), on transition zone with mat 2 (green curve) and on transition zone with mat 1 (red curve). (For interpretation of the references to colour in this figure caption, the reader is referred to the web version of this article.)

Table 3

Average of the vertical deflection of the rail in mm - Results of EMW measurements performed in Chauconin transition zone in 2008 and 2011.

\begin{tabular}{llll}
\hline & BT & TZ with MAT2 & TZ with MAT1 \\
\hline 2008 & $-0.55 \mathrm{~mm}$ & $-1.51 \mathrm{~mm}$ & $-2.32 \mathrm{~mm}$ \\
2011 & $-0.50 \mathrm{~mm}$ & $-1.4 \mathrm{~mm}$ & $-2.05 \mathrm{~mm}$ \\
\hline
\end{tabular}

spond to the low frequency (below $40 \mathrm{~Hz}$ ) trends of receptance curves in Fig. 15. The table confirms that this is indeed the case.

As a further illustration of sensitivity to substructure properties, measures at the transition between substructure designs are presented in Fig. 16. The blue curve, corresponding to impacts on the rail at inter-sleeper just before the last sleeper of the ballasted track with classical design, is very similar to the blue curve of Fig. 15 which was measured far enough from the transition to not be affected by the change. However, in the frequency range between 0 and $40 \mathrm{~Hz}$, the shape is more curved than in the homoge-

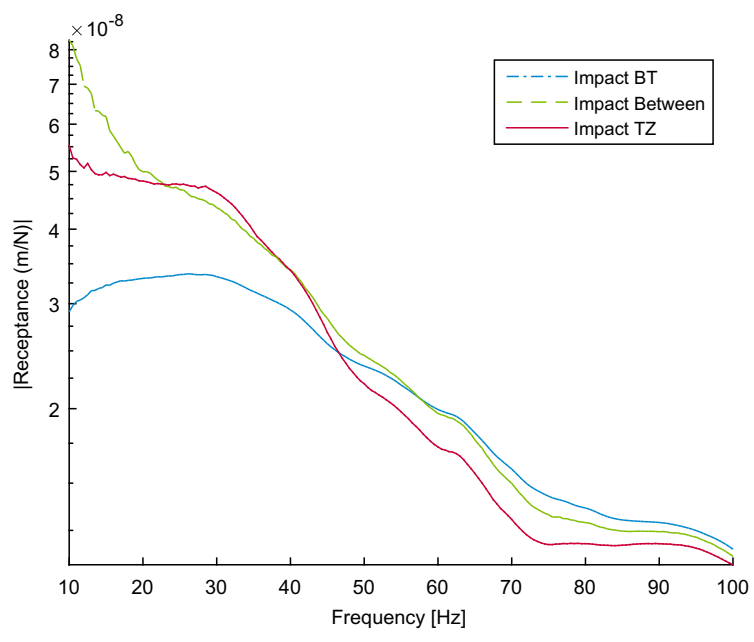

Fig. 16. Receptance curves measured directly at the transition between ballasted track and transition zone with mat 2 .

neous area, affected by the presence of the mat and cement bound capping layer below the neighboring sleeper. The green curve presents the response at the last sleeper of the ballasted track, the shape becomes closer to the ballast mat area (green curve in Fig. 15), with higher amplitudes before $60 \mathrm{~Hz}$. Finally, the red curve is measured on the first sleeper of the area with mat. Its shape is similar to the one of the homogeneous area, but between 40 and $60 \mathrm{~Hz}$ the response is still affected by the classical ballasted track, as the amplitude is higher.

\section{Numerical model}

While the receptance tests provide a reference sensitive to substructure properties, they do not give understanding of the exact contributions of various layers. This motivates the use of the numerical model for comparisons.

Three different meshes are used to model the ballasted track, the transition zone with mat 1 and the transition zone with mat 2 . Model properties for the ballasted track were described in Section 'Model description'. Additional material properties for the transition zone are summarized in Table 4. Mat material properties have been taken in the range given by Costad'Aguiar et al. (2015) and adjusted to fit measured curves. The geometrical properties chosen were shown in Fig. 12. As the recomposing by inverse Fourier transform requires identical slices, the three models are computed separately. For the transition zone with mat 2 , the inclination of the mat is not taken into account, which

Table 4

Material properties.

\begin{tabular}{lllll}
\hline & $E(\mathrm{MPa})$ & $v$ & $\rho\left(\mathrm{kg} / \mathrm{m}^{3}\right)$ & $\xi$ \\
\hline Mat 1 & 0.33 & 0.3 & 900 & 0.25 \\
Mat 2 & 0.24 & 0.3 & 900 & 0.25 \\
Cement bound layer & 23,000 & 0.25 & 2000 & 0.04 \\
Soil layer 1 & Gradient & 0.2 & 1800 & 0.04 \\
Soil layer 2 & Gradient & 0.2 & 1800 & 0.04 \\
\hline
\end{tabular}


is not a strong hypothesis as the slope of the mat is only of $0.15^{\circ}$. As in experiments the loading is not symmetric, the two track rails are modeled and the impact is applied on one side.

To identify soil parameters, geological investigations performed before the line construction are used. These investigations revealed that the soil is composed of two layers: the first one of clay which is $3.8 \mathrm{~m}$ high above a limestone marl layer. The values of approximate seismic wave speed in these materials are given in Pecker (2011) and recalled in Table 5. These values are used to define Young Modulus and Poisson ratio in soil as

$$
\left\{\begin{array}{l}
v=\frac{c_{p}^{2}-2 c_{s}^{2}}{2\left(c_{p}^{2}-c_{s}^{2}\right)} \\
E=\frac{\rho c_{s}^{2}\left(3 c_{p}^{2}-4 c_{s}^{2}\right)}{\left(c_{p}^{2}-c_{s}^{2}\right)}
\end{array}\right.
$$

The coefficient $n$ of Eq. (13) is set to 0.5 , the target Young modulus value is $75 \mathrm{Mpa}$ at $1 \mathrm{~m}$ depth in the first layer and a target value of $400 \mathrm{MPa}$ at $1 \mathrm{~m}$ of depth in the second and deepest soil layer are chosen.

To verify that the influence of lateral boundaries on rail displacement remains negligible in this model, a parametric study on the chosen soil width is presented in Fig. 17 with the fixed soil depth defined for Chauconin test site. The varying parameter is L, as defined on Fig. 9. Clearly in this configuration, the variation of this parameter has little impact on the main receptance peaks. Smaller peaks due to lateral reflections are indeed changing, but their impact on the receptance backbone is not significant, at least compared to the major changes due to substructure design that will be detailed next. Thus the effect of the artificial boundary can indeed be neglected.

Table 5

P and S seismic wave speed (from Pecker, 2011).

\begin{tabular}{lll}
\hline Material & $c_{p}[\mathrm{~m} / \mathrm{s}]$ & $c_{s}[\mathrm{~m} / \mathrm{s}]$ \\
\hline Clay & 150 & $100-150$ \\
Limestone marl & $1500-2000$ & $400-600$ \\
\hline
\end{tabular}

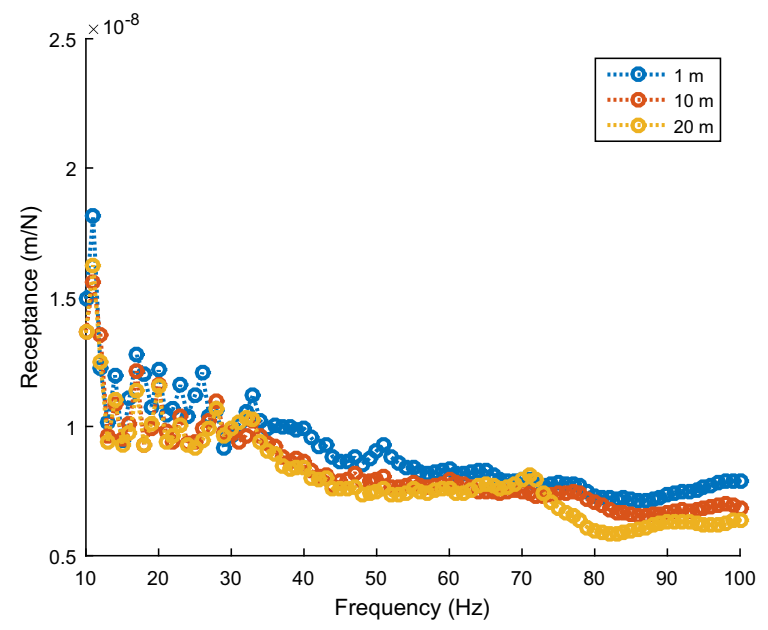

Fig. 17. Comparison of receptance curves considering several soil widths for Chauconin ballasted track configuration.

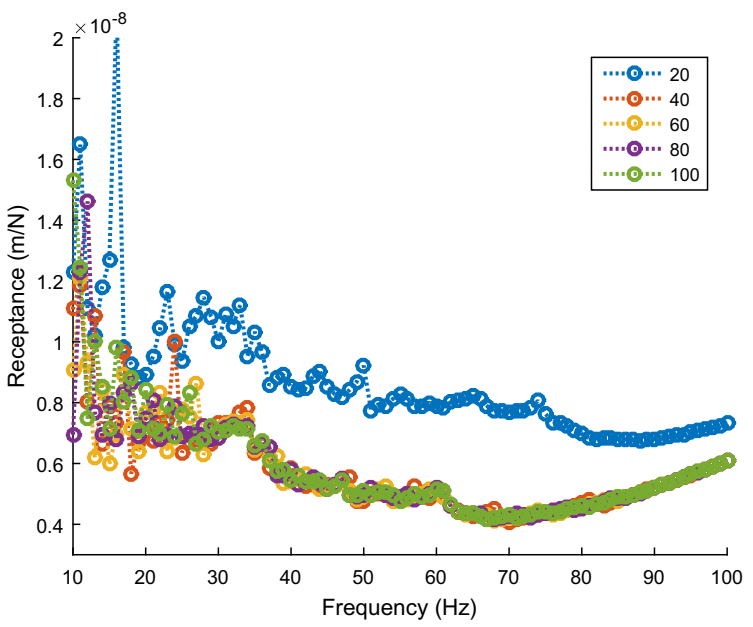

Fig. 18. Influence of the number of wavenumbers chosen on receptance curve for the ballasted track configuration.

As detailed in Section '3D FEM with Floquet transform', the computation method requires a choice on the spatial discretisation in Eq. (8): the number of wavelengths used for the inverse Fourier transform. Fig. 18 illustrates that the discretization has to be small enough to be able to follow frequency shifts in the dispersion diagram. A choice of eighty wavenumbers was here chosen as best compromise between accuracy of the result and computational time which is directly proportional to the number of wavenumbers selected. It is also useful to insist on the fact that variations of smaller peaks are not of particular interest, when compared to the major shifts due to track design and considering the influence of boundary conditions and soil property variability.

\section{Comparison between measurement and numerical model}

Based on the sensitivity analysis of the previous section, an additional soil width of $15 \mathrm{~m}$ is considered to model the Chauconin areas. Eq. (8) is solved for eighty values of wavenumber, using a discretization of $0.5 \mathrm{~Hz}$ in frequency for the periodic modes calculation. The spacing of wavenumbers is uneven, a log spacing with 40 values is used between 0 and 1 , and a $\log$ spacing for another set of 40 values is taken between 1 and $2 \pi$.

The computations corresponding to the three test areas are shown with markers in Fig. 19. The global curve levels and shapes are very similar to the experiments. Resonance peaks of the areas with mat are found at the same frequencies in model as in experimental results. Below $50 \mathrm{~Hz}$, the transition zone with mat 1 is the most flexible, then it is the ballasted track. The receptance curves of areas with mat are crossing the curve of ballasted track at $50 \mathrm{~Hz}$, which is the same value as in experiments for transition zone with mat 1 . At all frequencies, transition zone with mat 1 is softer than the one with mat 2, as observed in experiments.

However, differences can be noticed. The first is a lower response level in the ballasted track. The second is a wider 


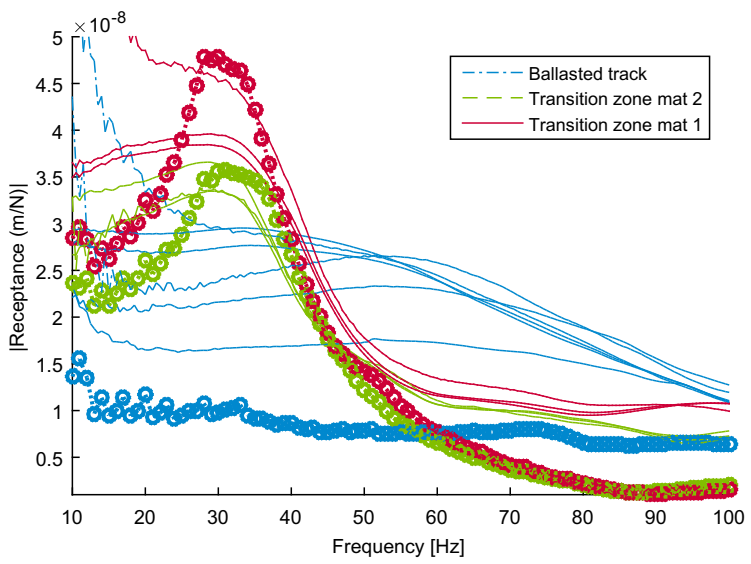

Fig. 19. Comparison between experimental (no markers) and computed (with markers) receptance function for ballasted track (blue) and transition zone (in green with mat 2, in red with mat 1) in Chauconin test site. (For interpretation of the references to colour in this figure caption, the reader is referred to the web version of this article.)

experimental peak for the transition zones. While understanding the origin of these differences remains a challenge, sources of discrepancies are known. Heterogeneities along the track will induce variations of the dispersion curve and thus widen peaks in the receptance. Ballast properties under and between sleepers are not constant and refinement of the current elastic model is probably needed.

\section{Interpretation of the receptance backbone}

A main advantage of models is the ability to analyze the response everywhere in the track.

In the present study initial computations assumed a symmetric track. But the impact occurs on a single rail and, in particular for the ballasted track, an antisymmetric mode can be found at $33 \mathrm{~Hz}$ and is displayed on Fig. 20(a). The displacement associated to this fre-

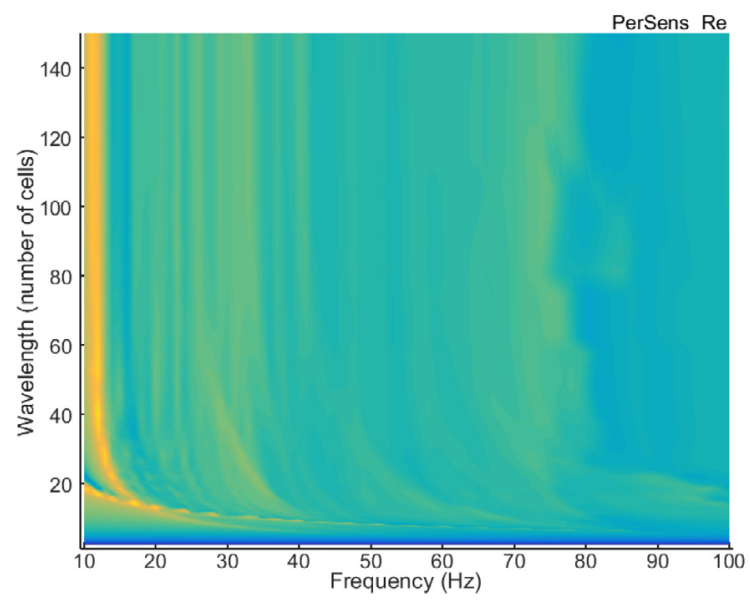

(a) Ballasted Track

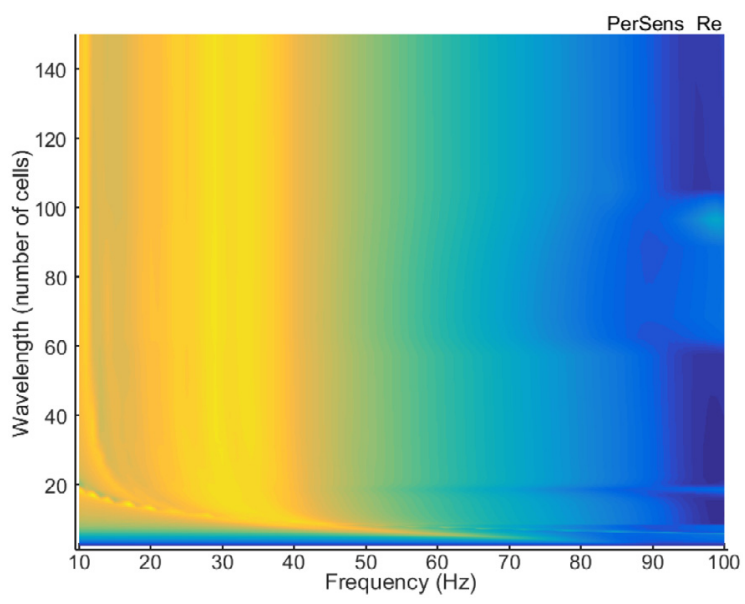

(b) Transition Zone with MAT2

Fig. 21. Decomposition of receptance in frequency and wavelength domains for ballasted track and transition zone. Colour is proportional to the vertical displacement from yellow (high displacement) to dark blue (no displacement). (For interpretation of the references to colour in this figure caption, the reader is referred to the web version of this article.)

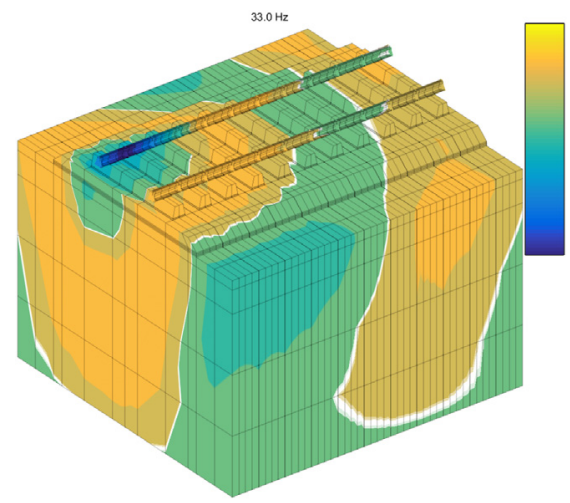

(b) Displacement under impact at $33 \mathrm{~Hz}$

(a) Periodic mode at $33 \mathrm{~Hz}$ for $n_{c x}=50$ number of slices

Fig. 20. Periodic mode of the ballasted track at $33 \mathrm{~Hz}$ and displacement under impact at this frequency. 


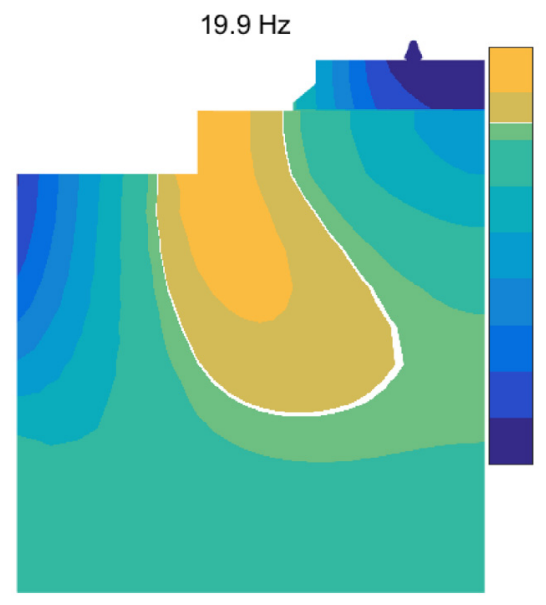

(a) TZ before resonance

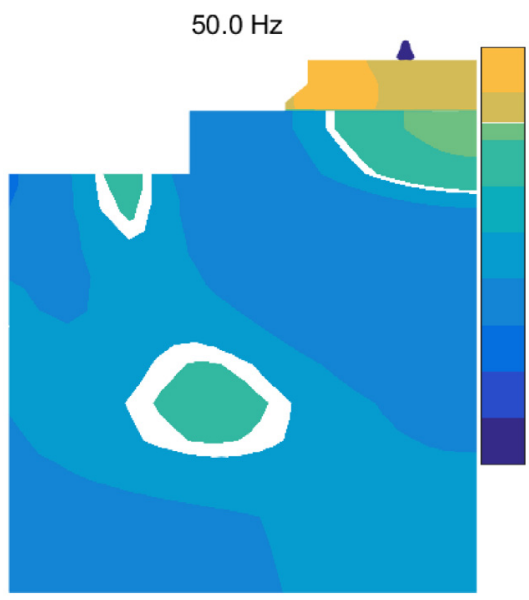

(b) TZ after resonance

Fig. 22. Cross section of $\mathrm{TZ}$ displacement. White line corresponds to zero response.

quency response is displayed in Fig. 20(b), the impact loading point is on the first visible slice. This contribution is clearly necessary to explain levels visible in the test (see Fig. 19).

Comparing the frequency/wavenumber decomposition of the receptances for ballasted and transition zones in Fig. 21, two main differences clearly appear

- Before $50 \mathrm{~Hz}$, the amplitude is globally higher for all wavelengths in the transition zone than in the ballasted track, with an important vertical mode at $35 \mathrm{~Hz}$ which does not appear in the ballasted track.

- After $50 \mathrm{~Hz}$, the effect is reversed with an amplitude lower in the transition zone than in the ballasted track. For the transition zone, an anti-resonance with very low displacements is visible near $60 \mathrm{~Hz}$.

The combination of resonance followed by an antiresonance is a classical characteristic of isolation systems. In case of the transition zone with mats, the top layers (superstructure and ballast) are suspended above the mat. This suspension mode is found at $35 \mathrm{~Hz}$ for long wavelengths and appears as a peak in the receptance. Above the suspension mode, the isolation starts to kickin and the level drops below that of the nominal design around $50 \mathrm{~Hz}$. Around $60 \mathrm{~Hz}$, the flexibility of the platform no longer has a small effect and the isolation loses its efficiency leading to visible anti-resonance.

To confirm this analysis Fig. 22 shows two crosssections of displacement in the transition zone with mat. The response at $19.9 \mathrm{~Hz}$, before the resonance over the mat, shows in phase motion of ballast and soil. The line of zero response, shown in white, isolates an area at the edge of the track. At $50 \mathrm{~Hz}$, after the resonance, the line of zero response, occurs within the mat on the edge of the ballast and slightly below at the centre of the track. Thus the expected phase opposition between ballast and soil motion is shown, which is characteristic of the isolation.

\section{Conclusion}

A methodology to compute track response in the frequency-wavenumber domain taking into account the 3D geometry of track has been introduced. To ease its use, it was shown that strategies to optimize computational time by using modal synthesis method and uneven wavenumber discretization were essential. Studying the impact of finite boundaries was also deemed critical because the authors are developing model reduction techniques to use similar geometries for time-domain nonlinear transient simulations. Finite soil depth is to be used with caution, knowing the real geological properties of the track. Finite soil width was shown in the present case to have small effects on the receptance backbone. Study of vibrations away from the track would however probably require the introduction of absorbing boundary conditions, for instance combined with infinite elements (as in Kouroussis et al., 2011 or Connolly et al., 2013).

For track design applications, the main contribution was to demonstrate the sensitivity of the receptance to the track substructure properties and to show how the proposed models could be used to analyze a change in configurations. On the dynamic analysis side, peaks in the receptance were shown to correspond to accumulation of periodic modes and not to a global resonance or eigenmode of the track. To perform this analysis, the decomposition of the receptance in a frequency/wavelength representation and the associated visualization of periodic modes were shown to be useful.

On the experimental side, receptance tests in an area presenting different substructures demonstrated significant effects with fairly clear changes over the frequency band below $100 \mathrm{~Hz}$. The numerical models were then used to demonstrate that the main effect could, in this case, be explained as a resonance of the superstructure and ballast on relatively soft mats.

The model reduction techniques of Arlaud et al. (2016), while initially meant for time domain transients with vari- 
able properties, can also be used to gain orders of magnitude in computation time for the responses shown here. Establishing the domain of validity of these models is thus seen as a process where part of the computations shown here will be used as reference. Sensitivity to variability along the track and uneven properties of ballast under and between sleepers also seem important topics to address.

\section{References}

Alves Costa P, Calçada R, Silva Cardoso A. Ballast mats for the reduction of railway traffic vibrations. Numer Study Soil Dyn Earthquake Eng 2012;42:137-50.

Alves Costa P, Calçada R, Silva Cardoso A. Track-ground vibrations induced by railway traffic: in situ measurements and validation of a 2.5D FEM-BEM model. Soil Dyn Earthquake Eng 2012;32:111-28.

Araújo N. High-speed trains on ballasted railway track [Ph.D. thesis]. Portugal: Universidade do Minho; 2010.

Arlaud E, Aguiar SCD, Balmes E. A numerical tool to assess the dynamic behaviour of different track designs. In: Railway engineering, Edinburgh.

Arlaud E, Aguiar SCD, Balmes E, Faussurier G. A numerical study of railway track dynamics : the case of a transition zone dynavoie method. In: Proceedings of the third international conference on railway technology: research, development and maintenance.

Balmes E. Viscoelastic vibration toolbox, User Manual, SDTools; 20042013.

Balmes E, Germes S. Design strategies for viscoelastic damping treatment applied to automotive components. Dearborn: IMAC; 2004.

Balmes E, Rebillat M, Arlaud E. Wave damping and evanescence : how to combine the spatial and temporal visions of the same problem? In: CFA 2016/VISHNO. p. 2495-501.

Banimahd M, Woodward PK. 3-Dimensional finite element modelling of railway transitions. In: Proceedings of ninth international conference on railway engineering, London.

Bathe K-J. Finite element procedures. Klaus-Jurgen Bathe; 2006.

Berggren EG, Kaynia AM, Dehlbom B. Identification of substructure properties of railway tracks by dynamic stiffness measurements and simulations. J Sound Vib 2010;329(19):3999-4016. http://dx.doi.org/ 10.1016/i.jsv.2010.04.015. URL http://linkinghub.elsevier.com/ retrieve/pii/S0022460X10002671.

Biarez J, Hicher PI. Elementary mechanics of soil behaviour. Saturated remoulded soils. A.A. Balkema; 1994.

Campos J, deRus G. Some stylized facts about high-speed rail: a review of HSR experiences around the world. Transp Policy 2009;16(1):19-28. http://dx.doi.org/10.1016/i.tranpol.2009.02.008. URL <http:// www.sciencedirect.com/science/article/pii/S0967070X09000109>.

Chebli H, Clouteau D, Schmitt L. Dynamic response of high-speed ballasted railway tracks: 3D periodic model and in situ measurements. Soil Dyn Earthquake Eng 2008;28(2):118-31. doi: http://dx.doi.org/10.1016/j.soildyn.2007.05.007. URL http:// www.sciencedirect.com/science/article/pii/S0267726107000656.

Collet M, Ouisse M, Ruzzene M, Ichchou MN. Floquet-Bloch decomposition for the computation of dispersion of two-dimensional periodic, damped mechanical systems. Int J Solids Struct 2011;48 (20):2837-48. http://dx.doi.org/10.1016/i.ijsolstr.2011.06.002. URL http://dx.doi.org/10.1016/j.ijsolstr.2011.06.002.

Connolly D, Giannopoulos A, Forde M. Numerical modelling of ground borne vibrations from high speed rail lines on embankments. Soil Dyn Earthquake Eng 2013;46:13-9. http://dx.doi.org/10.1016/ i.soildyn.2012.12.003. URL http://www.sciencedirect.com/science/ article/pii/S026772611200262X.

Connolly D, Kouroussis G, Giannopoulos A, Verlinden O, Woodward P, Forde M. Assessment of railway vibrations using an efficient scoping model. Soil Dyn Earthquake Eng 2014;58(0):37-47. doi:http://dx.doi. org/10.1016/j.soildyn.2013.12.003. URL http://www.sciencedirect. com/science/article/pii/S0267726113002662.

Costad'Aguiar S, Arlaud E, Potvin R, Laurans E, Funfschilling C. Railway transitional zones: a case history from ballasted to ballastless track. Int J Rail Technol 2015;2(3).

Esveld C. Innovation in railway track. TU Delft; 1997.

Fernandes VA, Lopez-Caballero F, d'Aguiar SC. Probabilistic analysis of numerical simulated railway track global stiffness. Comput Geotech 2014;55(0):267-76. doi:http://dx.doi.org/10.1016/j.compgeo.2013.
09.017. URL http://www.sciencedirect.com/science/article/pii/ S0266352X13001535.

François S, Schevenels M, Galvín P, Lombaert G, Degrande G. A 2.5D coupled FE/BE methodology for the dynamic interaction between longitudinally invariant structures and a layered halfspace. Comput Methods Appl Mech Eng 2010;199(23 - 24):1536-48. doi:http:// dx.doi.org/10.1016/j.cma.2010.01.001. URL http://www. sciencedirect.com/science/article/pii/S0045782510000022.

Hall L. Simulations and analysis of train-induced ground vibrations in finite element models. Soil Dyn Earthquake Eng 2003;23:403-13.

Ju S, Li H. Dynamic interaction analysis of trains moving on embankments during earthquakes. J Sound Vib 2011;330(22):5322-32. doi:http:// dx.doi.org/10.1016/j.jsv.2011.05.032. URL http://www.sciencedirect. com/science/article/pii/S0022460X1100472X.

Kaewunruen S, Remennikov AM. Field trials for dynamic characteristics of railway track and its components using impact excitation technique. NDT \& E Int 2007;40(7):510-9. doi:http://dx.doi.org/10.1016/j. ndteint.2007.03.004. URL http://www.sciencedirect.com/science/ article/pii/S0963869507000473.

Knothe $\mathrm{K}, \mathrm{Wu} \mathrm{Y}$. Receptance behaviour of railway track and subgrade. Arch Appl Mech 1998;68(7-8):457-70. http://dx.doi.org/10.1007/ s004190050179. URL <http://dx.doi.org/10.1007/s004190050179>.

Komatitsch D, Tromp J. A perfectly matched layer absorbing boundary condition for the second-order seismic wave equation. Geophys I Int 2003;154(1):146-53. URL http://wwwpapers://2ee5b6b1-9ec64645-855c-1ac4fb8101af/Paper/p625.

Kouroussis G, Verlinden O, Conti C. Free field vibrations caused by highspeed lines: Measurement and time domain simulation. Soil Dyn Earthquake Eng 2011;31(4):692-707. doi:http://dx.doi.org/10.1016/ j.soildyn.2010.11.012. URL http://www.sciencedirect.com/science/ article/pii/S0267726110002769.

Kouroussis G, Connolly D, Verlinden O. Railway-induced ground vibrations ? A review of vehicle effects. Int J Rail Transp 2014;2 (2):69-110. http://dx.doi.org/10.1080/23248378.2014.897791. URL <http://www.tandfonline.com/doi/full/10.1080/23248378.2014. 897791>.

Mace BR, Duhamel D, Brennan MJ, Hinke L. Finite element prediction of wave motion in structural waveguides. J Acoust Soc Am 2005;117 (5):2835. http://dx.doi.org/10.1121/1.1887126. URLhttp://link.aip. org/link/JASMAN/v117/i5/p2835/s1\&Agg=doi

Maes J, Sol H, Guillaume P. Measurements of the dynamic railpad properties. J Sound Vib 2006;293(3-5):557-65. http://dx.doi.org/ 10.1016/i.jsv.2005.08.042. URL http://www.sciencedirect.com/ science/article/pii/S0022460X05007625.

Man APD. Dynatrack: a survey of dynamic railway track properties and their quality [PhD]. Delft University; 2002.

Mishra D, Qian Y, Huang H, Tutumluer E. An integrated approach to dynamic analysis of railroad track transitions behavior. Transp Geotech. doi: http://dx.doi.org/10.1016/j.trgeo.2014.07.001. URL <http://www.sciencedirect.com/science/article/pii/ S2214391214000221>.

Momoya Y, Takahashi T, Nakamura T. A study on the deformation characteristics of ballasted track at structural transition zone by multi-actuator moving loading test apparatus. Transp Geotech. doi: http://dx.doi.org/10.1016/j.trgeo.2015.11.001. URL <http:// www.sciencedirect.com/science/article/pii/S2214391215000343>.

Oregui M, Li Z, Dollevoet R. An investigation into the modeling of railway fastening. Int J Mech Sci. doi: http://dx.doi.org/10.1016/j.ijmecsci. 2014.11.019. URL < http://www.sciencedirect.com/science/article/pii/ S0020740314003932>, <http://linkinghub.elsevier.com/retrieve/pii/ S0020740314003932>.

Oregui M, Li Z, Dollevoet R. Identification of characteristic frequencies of damaged railway tracks using field hammer test measurements. Mech Syst Signal Process 2015;54:224-42.

Paixão A, Fortunato E, Calçada R. The effect of differential settlements on the dynamic response of the train-track system: A numerical study. Eng Struct 2015;88:216-24. $\quad$ http://dx.doi.org/10.1016/j. engstruct.2015.01.044. URL http://www.sciencedirect.com/science/ article/pii/S0141029615000656.

Pecker A. Dynamique des structures et des ouvrages. Presse de l'école Nationale des Ponts et Chaussées; 2011.

Ribeiro ACCA. Transiçoes aterro - estrutura em linhas ferroviarias em alta velocidade: analise experimental e numérica [Phd]. FEUP; 2012.

Sayeed MA, Shahin MA. Three-dimensional numerical modelling of ballasted railway track foundations for high-speed trains with special reference to critical speed. Transp Geotech 2016;6:55-65. http://dx.doi.org/10.1016/i.trgeo.2016.01.003. URL http:// www.sciencedirect.com/science/article/pii/S2214391216000052. 
Shahraki M, Warnakulasooriya C, Witt KJ. Numerical study of transition zone between ballasted and ballastless railway track. Transp Geotech doi: http://dx.doi.org/10.1016/j.trgeo.2015.05.001. URL <http:// www.sciencedirect.com/science/article/pii/S2214391215000094>.

Shan Y, Albers B, Savidis Sa. Influence of different transition zones on the dynamic response of track? Subgrade systems. Comput Geotech 2013;48:21-8. http://dx.doi.org/10.1016/i.compgeo.2012.09.006. URI <http://linkinghub.elsevier.com/retrieve/pii/S0266352X12001887>.

Sodati G. Emw kiesen 2006 : gleiseinsenkungen mit dem einsenkungsmesswagen achslast 20 t. Tech. rep., SBB-report $(01 / 2007)$

Sternchüss A. Multi-level parametric reduced models of rotating bladed disk assemblies [Phd]. Ecole Centrale Paris; 2009.

Verbraken H, Degrande G, Lombaert G, Stallaert B, Cuellar V. Benchmark tests for soil properties, including recommendations for standards and guidelines. Project no. scp0-ga-2010-265754 rivas, RIVAS D1.11; 2013.
Wang P, Wang L, Chen R, Xu J, Xu J, Gao M. Overview and outlook on railway track stiffness measurement. J Modern Transp 2016;24 (2):89-102. $\quad$ http://dx.doi.org/10.1007/s40534-016-0104-8. URLhttp://link.springer.com/10.1007/s40534-016-0104-8.

Yang Y-b, Hung H-h. A 2.5 d finite/infinite element approach for modelling viscoelastic bodies subjected to moving loads. Int J Numer Methods Eng 2001;51(11):1317-36. http://dx.doi.org/ 10.1002/nme.208. URLhttp://doi.wiley.com/10.1002/nme.208.

Yang Y, Hung H, Chang D. Train-induced wave propagation in layered soils using finite/infinite element simulation. Soil Dyn Earthquake Eng 2003;23(4):263-78. doi:http://dx.doi.org/10.1016/S0267-7261 (03)00003-4. URL http://www.sciencedirect.com/science/article/pii/ S0267726103000034. 